\title{
Patient-reported Outcomes of Short-term Intra- articular Hyaluronic Acid for Osteoarthritis of the Knee: A Consecutive Case Series
}

\author{
Charles A. Gusho ${ }^{1}$, Mark Jenson ${ }^{2}$ \\ 1. Miscellaneous, Medical College of Wisconsin Green Bay, De Pere, USA 2. Family Medicine, Medical College of \\ Wisconsin Green Bay, De Pere, USA
}

Corresponding author: Charles A. Gusho, cgusho@mcw.edu

\section{Abstract \\ Background}

Supartz FX (Seikagaku Corp., Tokyo, Japan) has been investigated as a therapeutic for knee osteoarthritis (OA) due to its claimed preservation of viscoelastic joint properties and improvement in pain and physical function. The US prescribing information suggests patients may experience benefit with as few as three of five injections administered once weekly. However, recommended guidelines from the American Academy of Orthopaedic Surgeons (AAOS) do not support injectable hyaluronate due to controversial results of randomized controlled trials.

\section{Objective}

Do patients experience statistically and/or clinically significant improvement in disability scores following three injections?

\section{Methods}

A total of 32 patients with a mean age of $66 \pm 14$ years receiving Supartz FX were reviewed in a prospective, observational study. Functional outcome data via Western Ontario and McMaster Universities Osteoarthritis Index (WOMAC) scores for pain, stiffness, and physical function were collected at 0, 1, 2 and 3 weeks, and means were analyzed via paired t-test.

\section{Results}

Three injections at one-week intervals resulted in statistically significant improvement across all sub scores $(\mathrm{p}<0.05)$. Confidence intervals (CIs) of treatment effects (ES, 95\% CI) for pain $(0.27,95 \% \mathrm{CI} 0.99,1.26)$, stiffness $(0.17,95 \% \mathrm{CI} 0.50,0.67)$, and function $(0.55,95 \%$ CI $2.79,3.35)$ were recorded and compared to published minimum clinically important improvement (MCII) thresholds.

Received 06/03/2019

Review began 06/10/2019 Review ended 06/19/2019 Published 06/22/2019

() Copyright 2019

Gusho et al. This is an open access article distributed under the terms of the Creative Commons Attribution License CC-BY 3.0., which permits unrestricted use, distribution, and reproduction in any medium, provided the original author and source are credited.

\section{Conclusion}

Despite manufacturer recommendations, in this study short-term use of Supartz FX for knee OA does not meet clinically significant thresholds as the treatment effects for WOMAC sub scores fail to satisfy published MCII for pain (0.39), stiffness (0.39) and function (0.37). In light of these findings and in concordance with recommendations set forth by the AAOS, this study contributes to a preventative medicine database that encourages exploration of non-surgical and non-opiate modalities for the management of osteoarthritis.

Categories: Pain Management, Preventive Medicine, Orthopedics Keywords: osteoarthritis, hyaluronic acid, viscosupplementation

\section{Introduction}

Osteoarthritis (OA) is the most common joint disorder in the United States, affecting approximately 27 million Americans [1]. OA most commonly occurs in the knee, and one in two adults will develop symptoms of knee OA sometime in their lives [1]. Specifically, OA of the knee is due in part to a decreased viscosity of synovial fluid which normally acts as a cushion. A healthy joint is lubricated with 1-2 $\mathrm{mL}$ of synovial fluid containing 5 to $8 \mathrm{mg}$ of hyaluronic acid (HA) [2]. In the arthritic knee, however, HA is diminished, reducing the viscoelastic properties of the joint and increasing the stress on the articular surface, causing erosion, bone spurs, and pain [2].

Less severe forms of knee OA are commonly managed with intra-articular HA (IAHA) injections, though meta-analyses of randomized controlled trials have failed to identify significant clinical changes in outcomes between IAHA and placebo [3]. Balazs and Denlinger were the first to suggest IAHA use for restoration of viscoelastic properties and improved functionality, and several compounds with differing 
molecular weight, preparation of purified sodium hyaluronate, and injection schedules have since been introduced into clinical practice [4-5]. One such viscosupplement, Supartz FX (Seikagaku Corp., Tokyo, Japan), is administered as a $25 \mathrm{mg} / 2.5 \mathrm{~mL}$ intra-articular injection once weekly for five weeks, for a total of five injections [6].

Previous studies have explored the efficacy of high-molecular-weight HA models using Likert-type Western Ontario and McMaster Universities Osteoarthritis Index (WOMAC) scores for pain and physical function [78]. Additional studies have suggested improvement in WOMAC scores using Supartz FX followed out to 1, 3, and 6 months, with significant mean reduction at 26 weeks, and an overall delayed time to total joint arthroplasty [8-9]. However, according to US prescribing information, patients using Supartz FX may experience benefit after a minimum of three doses given at weekly intervals [10]. Therefore, the aim of this study was to analyze self-reported weekly percent improvements in pain, stiffness, and function using WOMAC scores following three consecutive Supartz FX injections in patients with knee OA.

\section{Materials And Methods}

\section{Study subjects}

Fifty-five patients (female $=27$ ) were screened to participate in this study. The inclusion criteria were unilateral knee OA (Kellgren-Lawrence Grade 2 or 3) confirmed by radiographs. The exclusion criteria were bilateral knee OA, previous IAHA, viscosupplementation, or corticosteroid injection into the knee less than three months from starting Supartz FX; concomitant knee disease, ligamentous instability on physical exam, and ongoing anticoagulant therapy.

\section{Study design}

As a consecutive case-series, patient-reported outcomes following Supartz FX were recorded using WOMAC scores before and one-week after each of three injections. WOMAC scores are based on five items related to pain (sub score: $0-20 ; 0=$ minimum pain sub score; $20=$ maximum pain sub score), 2 items related to stiffness (sub score 0-8; 0 = minimum stiffness sub score; 8 = maximum stiffness sub score), and 17 items related to physical activity (sub score $0-68 ; 0=$ minimum physical activity sub score; 68 = maximum physical activity sub score). The summed score is normalized to a total out of 100 .

\section{Statistical analysis}

WOMAC sub score data, computed to a normalized value of 100 , and mean percent reductions, were recorded at weeks $0,1,2$ and 3. Sub scores were analyzed using a paired 2-sample t-test. A value of $\mathrm{p}<0.05$ was considered statistically significant and data are represented as the mean \pm standard error (SE) of the mean. Weekly sub score changes were statistically analyzed for effect size at a 95\% confidence interval and compared to published minimum clinically important improvement (MCII) thresholds.

\section{Results}

Thirty-two patients (females $=19)$ aged between 35-89 $(66 \pm 14$; mean \pm SD) met the inclusion criteria. The average weight was $95.3 \pm 27.1 \mathrm{~kg}$, and the average height was $1.67 \pm 0.11 \mathrm{~m}$. The average body mass index (BMI) as $34.2 \pm 7.9 \mathrm{~kg} / \mathrm{m} 2.23$ patients were obese (BMI $\geqslant 30.00 \mathrm{~kg} / \mathrm{m} 2$ ), seven were overweight (BMI 25.00$29.99 \mathrm{~kg} / \mathrm{m} 2$ ), and two patients were considered normal weight (BMI 18.5-24.99 kg/m2). Percent mean improvement (\%) in WOMAC sub scores were recorded weekly (Figure 1).

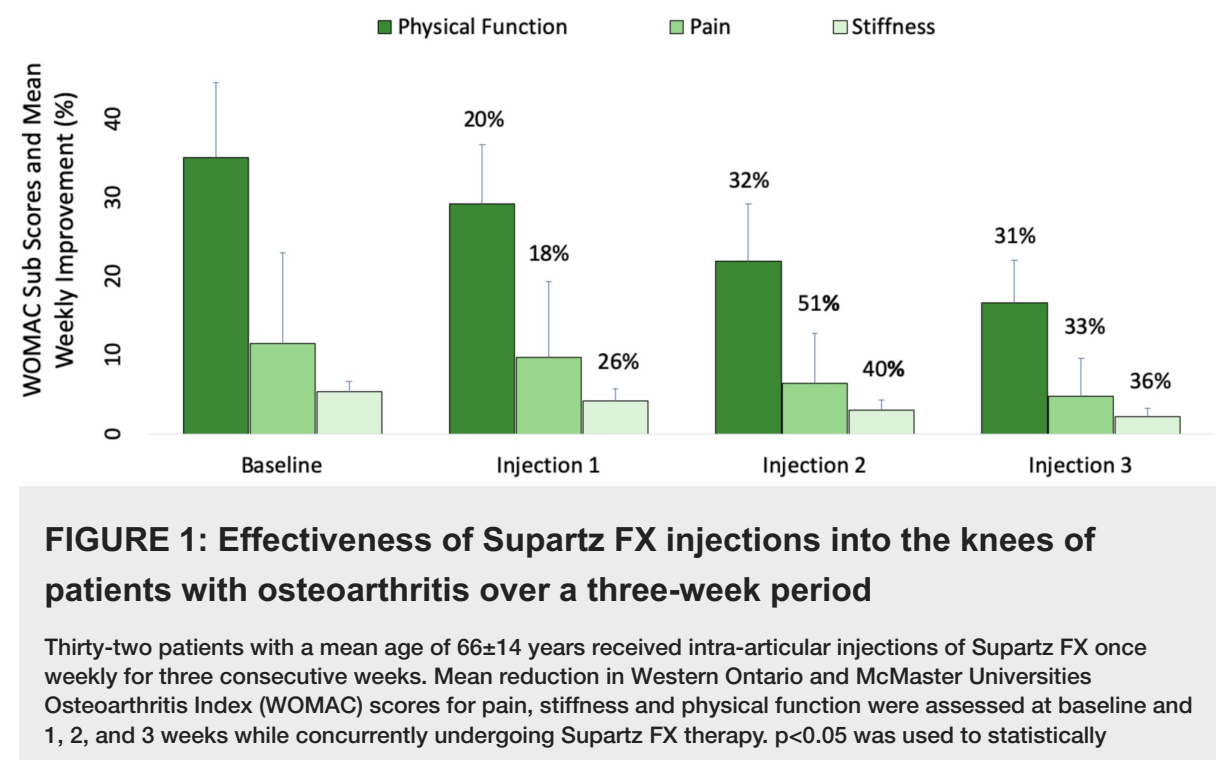




\section{Cureus}

compare weekly mean values. $n=32$.

A decrease from "Baseline" sub scores for pain (11.5 \pm 2.7 ), stiffness (5.3 \pm 1.3 ), and physical function (35.1 \pm 9.6 )

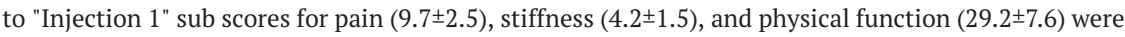
recorded. These and the subsequent values listed below are represented by each of the consecutive data bars in Figure 1.

A decrease from "Injection 1" sub scores for pain (9.7 \pm 2.5$)$, stiffness $(4.2 \pm 1.5)$, and physical function

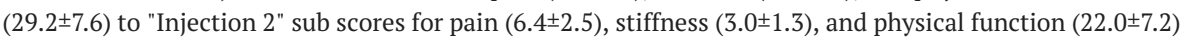
were recorded.

A decrease from "Injection 2" sub scores for pain (6.4 \pm 2.5$)$, stiffness (3.0 \pm 1.3$)$, and physical function

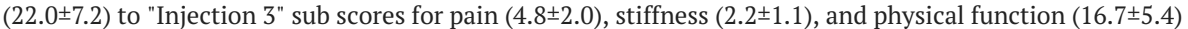
were recorded.

Scores for the obese cohort (BMI $\geqslant 30.00 \mathrm{~kg} / \mathrm{m} 2$ ) were analyzed by comparing baseline values of physical function only to those after the third injection. Neither mean percent improvement nor statistical significance were used to evaluate these specific changes within the obese group (Figure 2).

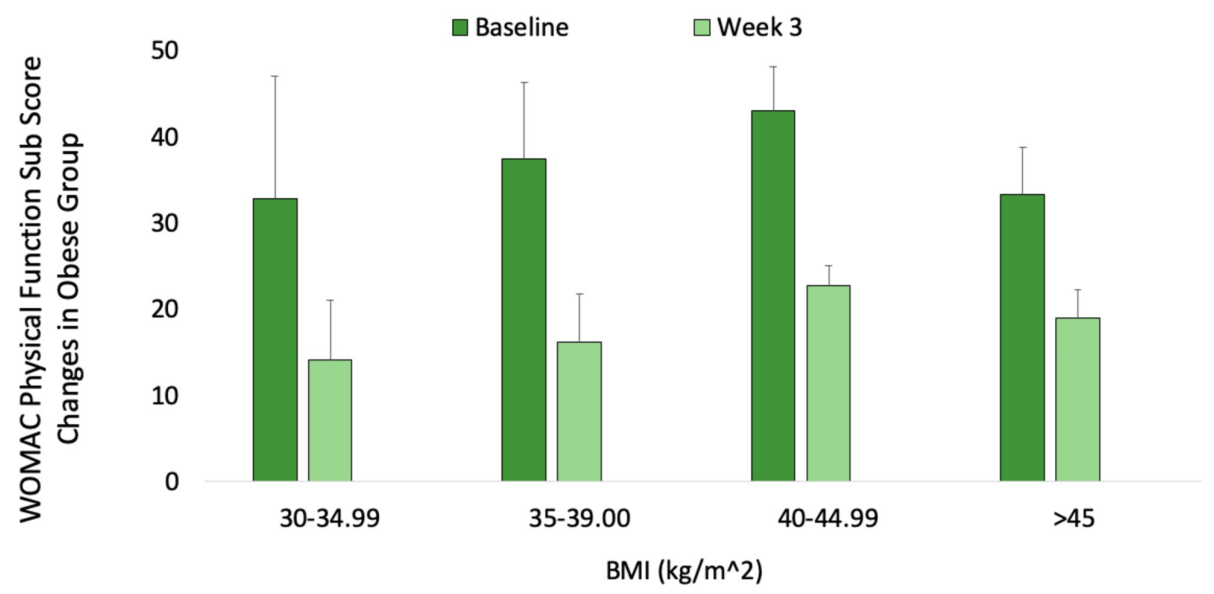

FIGURE 2: Mean reduction in Western Ontario and McMaster Universities Osteoarthritis Index (WOMAC) disability scores following Supartz FX injections into the knees of obese (BMI $\geq 30.00 \mathrm{~kg} / \mathrm{m} 2)$ patients

Weekly sub scores for physical function only were compared at baseline and at three weeks using BMI stratification of the obese group. Weekly percent changes are not included within this cohort. $n=23$.

Treatment effect sizes that were based upon weekly improvements in WOMAC sub scores are plotted against published MCII thresholds (Figure 3). 


\section{Cureus}
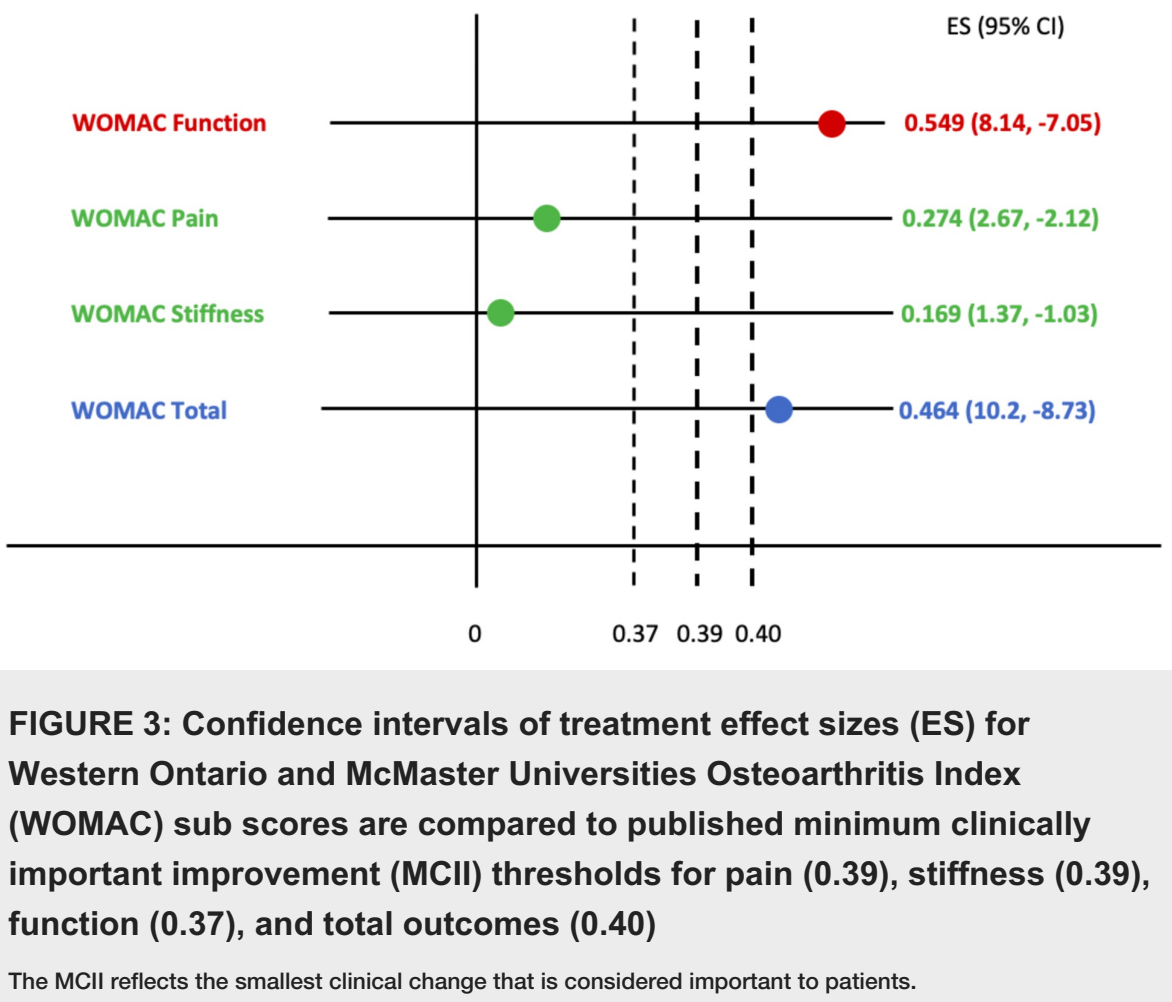

\section{Discussion}

This study evaluates the clinical meaningfulness of changes in self-reported patient outcomes following hyaluronic acid injections into the osteoarthritic knee. We were unable to identify any previous studies that analyze self-reported outcomes following a short-term, three-week Supartz FX injection schedule. As such, the results of this study suggest the greatest mean improvement (\%) occurs after just two injections, evidenced by the highest percent reduction in WOMAC scores occurs following the second injection $(p<0.05)$ (Figure 1). The percent value indicated above each of the weekly mean sub scores corresponds to the percent reduction in pain, stiffness, and physical function; the larger the percent reduction, the greater the improvement in functionality.

Statistical significance in and of itself provides data regarding sample size but does not incorporate the procedure's clinical significance to patients. Therefore, interpretation of results using MCII thresholds corroborates statistical significance by highlighting the smallest clinical change important to patients. Study results are considered clinically significant if the lower confidence interval of its treatment effect size is greater than the MCII, and not clinically significant if its upper confidence interval lies below or includes the MCII.

Variation may exist within different patient populations, causing discrepancies in what one patient considers clinically significant compared to another, either from subjective experience or baseline disease. However, the MCII serves as a reasonable proxy for evaluating meaningful improvement within populations of similar demographics. Thus, the MCIIs used here are derived from previously published data. In Guidelines for Treatment of Osteoarthritis of the Knee, the American Academy of Orthopaedic Surgeons (AAOS) used effect sizes reported by Angst et al. to compute thresholds for WOMAC sub scores of pain (0.39), function (0.37), stiffness (0.39), cumulative (0.40) [11].

Weekly mean sub score data shown in Figure 1 were analyzed for treatment effect size and compared to the above MCII thresholds (Figure 3). While statistically significant, these findings are only "possibly" clinically significant as the confidence intervals for each effect size include the MCII. Therefore, in concordance with the recommendations set forth by the AAOS, this study provides inconclusive evidence for short-term use of Supartz FX in the treatment or symptomatic management of knee osteoarthritis. While self-reported outcomes do show moderate improvement after two injections of Supartz FX, the changes are not considered clinically meaningful.

These results contribute to a discourse on osteoarthritis from an evidence-based medicine (EBM) perspective. EBM often incorporates the best evidence, clinical expertise, and patient wishes when making an informed decision. Therefore, while the evidence for use of IAHA is inconclusive (and not recommended 
by the AAOS), clinicians should exercise clinical judgment and accommodate patient preference when explaining the benefits and harms of IAHA. Certain groups of patients may respond better to intra-articular Supartz FX than others. For example, Figure 2 highlights decreasing self-reported WOMAC scores for patients of different BMI groups. Though not directly linear, a physician who believes in the efficacy of hyaluronic acid may be more likely to combine weight-loss efforts with injections for obese patients, to achieve potentially greater overall self-reported outcomes.

\section{Conclusions}

The use of intra-articular hyaluronic acid injections has been well studied, though evidence of improvement in pain, stiffness, and disability versus placebo has been controversial. Further data supporting its efficacy has been unconvincing, and the AAOS does not recommend the use of IAHA in clinical practice. Despite manufacturer recommendations, short-term use of Supartz FX for knee osteoarthritis does not meet clinically significant thresholds as the treatment effects for WOMAC sub scores fail to satisfy published MCII criteria.

\section{Additional Information \\ Disclosures}

Human subjects: Consent was obtained by all participants in this study. MCW/FH Institutional Review Board \#5 issued approval PRO00031549. The data procedures were carried out at the Dousman Clinic (Green Bay, Wisconsin) in accordance with the Helsinki declaration and Medical College of Wisconsin Internal Review Board (IRB) approval. Consent was obtained by all participants in the study. . Animal subjects: All authors have confirmed that this study did not involve animal subjects or tissue. Conflicts of interest: In compliance with the ICMJE uniform disclosure form, all authors declare the following: Payment/services info: All authors have declared that no financial support was received from any organization for the submitted work. Financial relationships: All authors have declared that they have no financial relationships at present or within the previous three years with any organizations that might have an interest in the submitted work. Other relationships: All authors have declared that there are no other relationships or activities that could appear to have influenced the submitted work.

\section{References}

1. Arthritis Foundation: what is osteoarthritis?. (2013). Accessed: November, 2018: http://www.arthritis.org/about-arthritis/types/osteoarthritis/what-is-osteoarthritis.php.

2. Madden CC, Putukian M, McCarty EC, Young CC: Netter's Sports Medicine. O'Grady E (ed): Saunders, Philadelphia; 2010.

3. Jevsevar D, Donnelly P, Brown G, Cummins D: Viscosupplementation for osteoarthritis of the knee: a systematic review of the evidence. J Bone Joint Surg Am. 2015, 97:2047-2060. 10.2106/JBJS.N.00743

4. Bannuru RR, Schmid CH, Kent DM, Vaysbrot EE, Wong JB, McAlindon TE: Comparative effectiveness of pharmacologic interventions for knee osteoarthritis: a systematic review and network meta-analysis. Ann Intern Med. 2015, 162:46-54. 10.7326/M14-1231

5. Cyphert JM, Trempus CS, Garantziotis S: Size matters: molecular weight specificity of hyaluronan effects in cell biology. J Cell Biol. 2015, 1-8. 10.1155/2015/563818

6. Altman R, Dasa V, Takeuchi J: Review of the mechanism of action for Supartz FX in knee osteoarthritis . Cartilage. 2018, 9.1:11-20. 10.1177\%2F1947603516684588

7. Karlsson J, Sjogren LS, Lohmander LS: Comparison of two hyaluronan drugs and placebo in patients with knee osteoarthritis: a controlled, randomized, double-blind, parallel-design multicentre study. Rheumatology (Oxford). 2002, 41:1240-8. 10.1093/rheumatology/41.11.1240

8. Bellamy N, Buchanan WW, Goldsmith CH, Campbell J, Stitt LW: Validation study of WOMAC: a health status instrument for measuring clinically important patient relevant outcomes to antirheumatic drug therapy in patients with osteoarthritis of the hip or knee. J Rheumatol. 1988, 15:1833-1840.

9. Altman R, Lim S, Steen R, Dasa V: Intra-articular hyaluronic acid delays total knee replacement in patients with knee osteoarthritis: evidence from a large U.S. health claims database. Osteoarthritis Cartilage. 2015, 23:403-404. 10.1016/j.joca.2015.02.746

10. Supartz ${ }^{\circledR}$ (sodium hyaluronate). (2007). Accessed: January 30, 2019: http://www.supartzfx.com/wpcontent/uploads/2015/07/SUPARTZ_FX_Package_Insert.pdf.

11. Jevsevar D, Brown GA, Jones DL, et al.: The American Academy of Orthopaedic Surgeons evidence-based guideline on treatment of osteoarthritis of the knee. J Bone Joint Surg. 2013, 95:1885-86. 